\title{
Anticonvulsant-induced dyskinesias: a comparison with dyskinesias induced by neuroleptics
}

\author{
D. CHADWICK, E. H. REYNOLDS, AND C. D. MARSDEN \\ From the University Department of Neurology, the Institute of Psychiatry, and \\ King's College Hospital Medical School, London
}

SYNOPSIS Anticonvulsants cause dyskinesias more commonly than has been appreciated. Diphenylhydantoin (DPH), carbamazepine, primidone, and phenobarbitone may cause asterixis. DPH, but not other anticonvulsants, may cause orofacial dyskinesias, limb chorea, and dystonia in intoxicated patients. These dyskinesias are similar to those caused by neuroleptic drugs and may be related to dopamine antagonistic properties possessed by DPH.

Overdosage with diphenylhydantoin (DPH) and other anticonvulsant drugs causes an acute syndrome of drowsiness, ataxia, dysarthria, and nystagmus (Woodbury et al., 1972). In recent years a variety of chronic neurological effects of the drugs have been recognised (Reynolds, 1975a) and a number of reports have noted abnormal involuntary movements (dyskinesias) occurring in patients acutely or chronically intoxicated with DPH. The descriptions of those dyskinesias have included chorea, athetosis, dystonia, tremor, and asterixis ${ }^{1}$ (Table 1). They are most often seen in patients with severe epilepsy and significant organic brain damage, taking multiple anticonvulsant drugs. They have been associated almost exclusively with toxic serum levels of DPH and have usually recovered rapidly with adjustment of dosage.

This communication describes a variety of dyskinesias occurring in patients intoxicated with DPH and other anticonvulsants, who were seen in a busy general neurological unit over a period of some 18 months. DPH and other anticonvulsants in intoxicating doses may cause asterixis, as well as a cerebellar syndrome. DPH, but not other anticonvulsants, appears capable of inducing a syndrome of orofacial

\footnotetext{
'We have used the term 'chorea' to denote unpredictable, rapid non-purposive muscular jerks of face, tongue, and limbs (which occur at rest and interrupt voluntary activity), and 'dystonia' to denote abnormal sustained muscular contractions which, if continued, result in the maintenance of typically dystonic postures, and if spasmodic, cause slow movements into such dystonic postures. We have avoided the terms 'athetosis' and 'choreoathetosis' as we believe them to be confusing. 'Asterixis' is used to describe irregular postural lapses and subsequent corrections, developing after a latent period, during sustained posture against gravity-for example, of the outstretched hands.
}

(Accepted 18 August 1976.) dyskinesia with distal chorea of the limbs and dys tonic spasms of axial and limb muscles. This syndromes $\vec{N}$ has occurred only when DPH is administered in doseso $\vec{N}$ causing toxic plasma levels and usually remits when? the dose is reduced. The dyskinesias produced bs DPH are reminiscent of those provoked by pheno thiazine or other neuroleptic drugs, suggesting similar cause.

CASE HISTORIES (Table 2)

CASE 1: ASTERIXIS AND CEREBELLAR SYNDROME DUE TO PHENOBARBITONE INTOXICATION

This patient was a 51 year old woman, working as a packer, who had suffered idiopathic grand mal seizures without aura since the age of 17 years. Her seizures has always been difficult to control in spite of taking regular anticonvulsant therapy for 24 years. For the previous 12 months she had been taking DPH $300 \mathrm{mg} /$ day, phenobarbitone $60 \mathrm{mg} /$ day, primidone $500 \mathrm{mg} /$ day, and diazepam $15 \mathrm{mg} /$ day.

She was referred with an episode of drowsiness, unsteadiness, and 'shakiness' of her hands. A similar episode had occurred six months previously and had lasted for three to four weeks.

On examination she was of below normal intelligence, with a childish personality. She showed a mild dysarthria, phasic nystagmus on lateral gaze, and a gait ataxia. There was marked asterixis of the outstretched hands, and the presence of these postural lapses resulted in some impairment of finger-nose coordination. There were no signs of liver disease.

Biochemical screening and liver function tests were normal with the exception of a raised plasma alkaline 


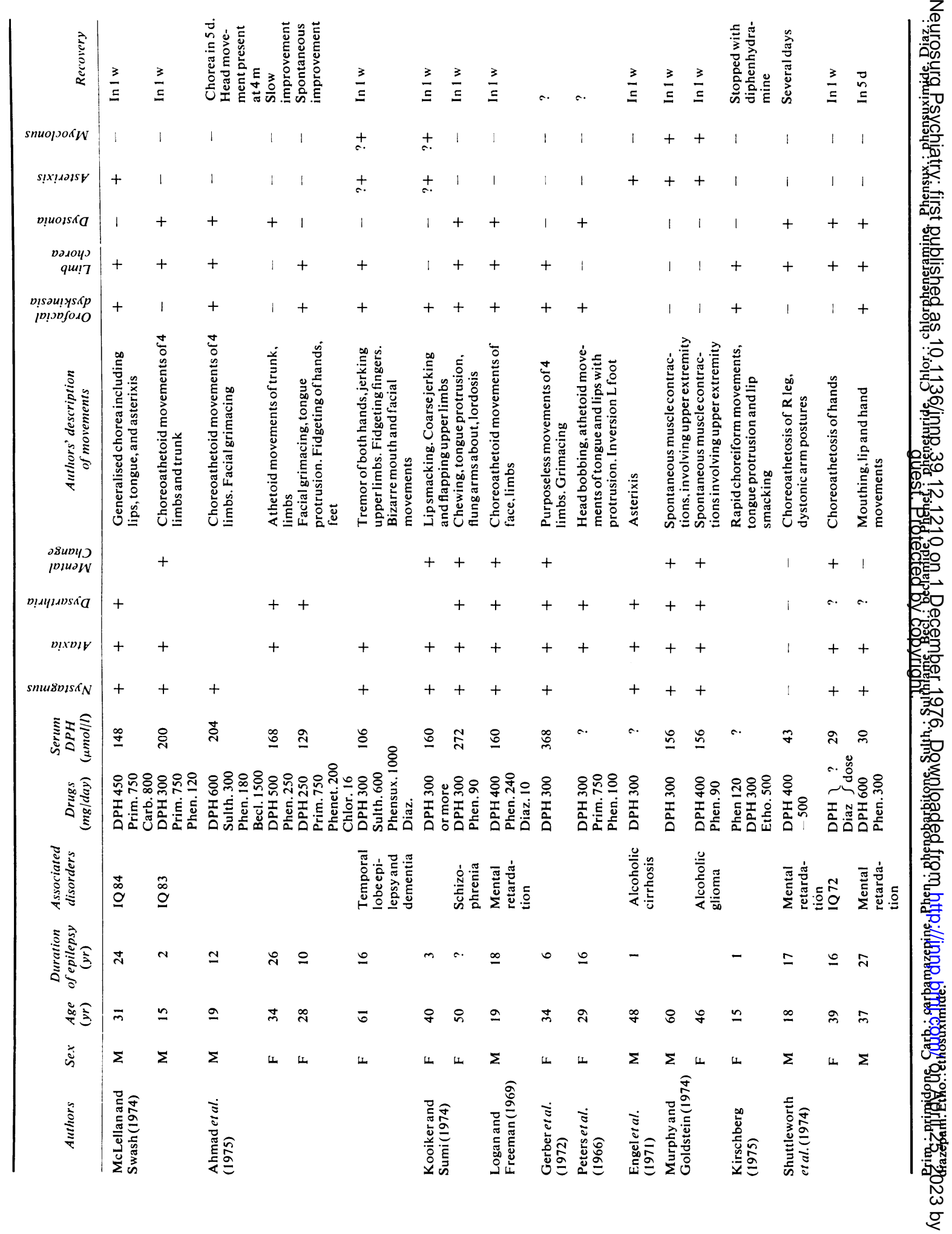




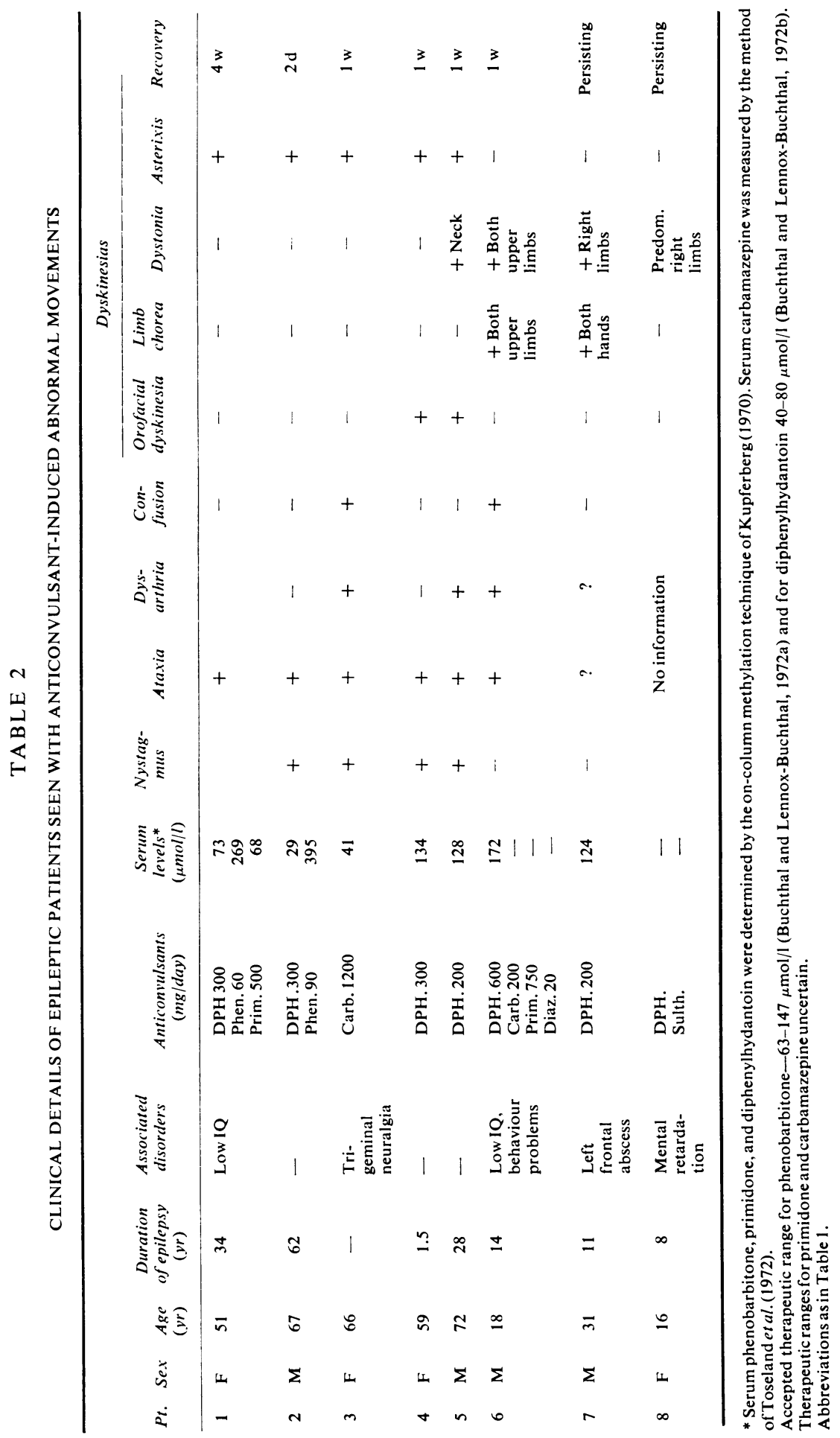


phosphatase (100 Iu/l). Anticonvulsant estimations revealed a serum phenobarbitone of $269 \mu \mathrm{mol} / 1$ $(64 \mu \mathrm{g} / \mathrm{ml})$.

Phenobarbitone was stopped and there was a rapid clinical improvement with disappearance of nystagmus and gait ataxia within three to four days (Figure). Repeat anticonvulsant levels done at this time showed a serum phenobarbitone of $135 \mu \mathrm{mol} / 1$ $(32 \mu \mathrm{g} / \mathrm{ml})$, primidone $67 \mu \mathrm{mol} / 1(15 \mu \mathrm{g} / \mathrm{ml})$, and DPH $49 \mu \mathrm{mol} / 1(12 \mu \mathrm{g} / \mathrm{ml})$. However, as minor asterixis was still present, the dose of primidone was reduced to $375 \mathrm{mg} /$ day. Eight weeks later the asterixis had completely disappeared and the serum phenobarbitone was $65 \mu \mathrm{mol} / 1(15.5 \mu \mathrm{g} / \mathrm{ml})$, primidone $8 \mu \mathrm{mol} / 1$ $(1.7 \mu \mathrm{g} / \mathrm{ml})$, and DPH $48 \mu \mathrm{mol} / 1(12 \mu \mathrm{g} / \mathrm{ml})$. However, at this time, seizure control deteriorated so the dose of primidone was increased to $500 \mathrm{mg} / \mathrm{day}$. This resulted in a reappearance of mild asterixis without other signs of anticonvulsant intoxication. Reestimation of serum anticonvulsant levels showed a phenobarbitone of $126 \mu \mathrm{mol} / \mathrm{l}(30 \mu \mathrm{g} / \mathrm{ml})$, primidone $40 \mu \mathrm{mol} / 1(6.5 \mu \mathrm{g} / \mathrm{ml})$, and DPH of $22 \mu \mathrm{mol} / 1(5.4$
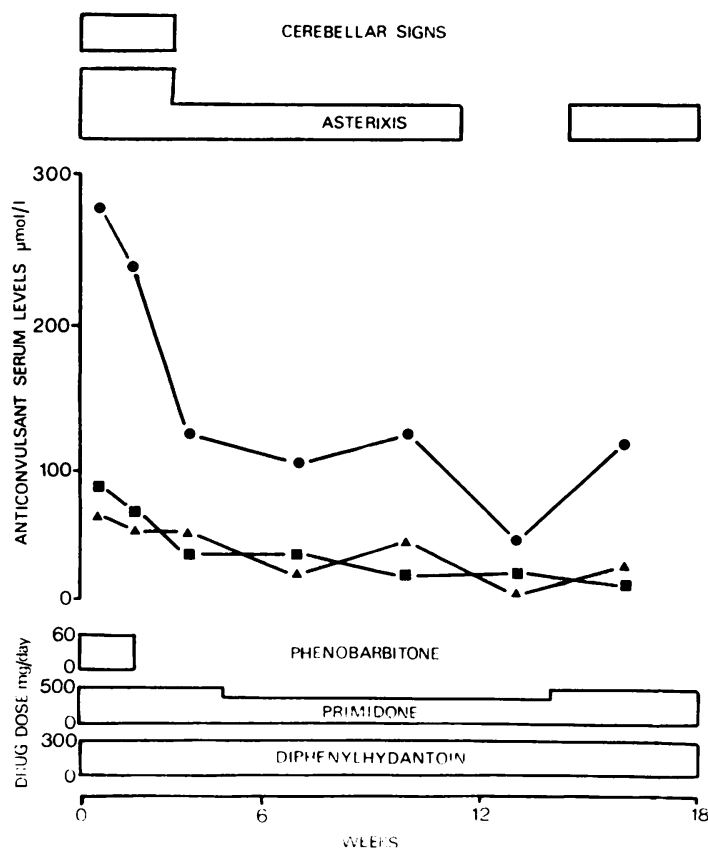

FIGURE Asterixis and cerebellar syndrome due to intoxication with phenobarbitone and primidone, in relation to serum anticonvulsant concentrations.

- - serum phenobarbitone

- A - serum primidone

- - serum DPH $\mu \mathrm{g} / \mathrm{ml})$. The patient's improved seizure control was such that she was willing to accept the minor asterixis and the inconvenience that this caused. The possibility that DPH might be responsible for her asterixis was considered and this drug was withdrawn. However, her asterixis persisted.

CASE 2: ASTERIXIS AND CEREBELLAR SYNDROME DUE TO PHENOBARBITONE INTOXICATION

A 67 year old man, who had had grand mal seizures in childhood, developed a recurrence of fits at the age of 58 years. Six months previously he had started therapy with phenobarbitone $90 \mathrm{mg} /$ day and DPH 300 $\mathrm{mg} / \mathrm{day}$.

Since then his family had noted an altered personality with increasing apathy. He was admitted to hospital complaining of a severe headache for a month. Investigations were negative apart from a variably raised ESR $(12-80 \mathrm{~mm} / \mathrm{h})$. (Serum anticonvulsants were not estimated.) He was treated with analgesics and diazepam and discharged. He returned one week later having been confused and unsteady at home.

On admission he was drowsy but orientated and showed a moderate gait ataxia, nystagmus, and marked asterixis of the outstretched hands. Investigations were again normal apart from serum anticonvulsants, phenobarbitone $395 \mu \mathrm{mol} / 1(94 \mu \mathrm{g} / \mathrm{ml})$, DPH $29 \mu \mathrm{mol} / 1(7 \mu \mathrm{g} / \mathrm{ml})$. The dose of phenobarbitone was decreased to $60 \mathrm{mg} /$ day and within two days the asterixis had disappeared to be followed shortly by marked improvement in the gait ataxia and nystagmus. One week later he was symptom free and serum phenobarbitone was $166 \mu \mathrm{mol} / \mathrm{l}(40 \mu \mathrm{g} / \mathrm{ml})$ and DPH $46 \mu \mathrm{mol} / \mathrm{l}(11.5 \mu \mathrm{g} / \mathrm{ml})$.

CASE 3: ASTERIXIS AND CEREBELLAR SYNDROME DUE TO CARBAMAZEPINE INTOXICATION

A 66 year old woman gave a two year history of tic douloureux affecting the right ophthalmic division of the trigeminal nerve. During this time her pain had been moderately well controlled by carbamazepine in doses of up to $800 \mathrm{mg} /$ day. She suffered a further exacerbation which resulted in inability to take solid food.

On admission she was dehydrated and unwell with phasic nystagmus on lateral gaze, a moderate gait ataxia, and asterixis of her outstretched hands. At this time the carbamazepine was increased to 1200 $\mathrm{mg} /$ day. On this dose the serum level of this drug was $41 \mu \mathrm{mol} / 1(9.7 \mu \mathrm{g} / \mathrm{ml})$ and she was confined to bed because of gross gait ataxia. The asterixis became more marked but her trigeminal neuralgia improved. Biochemical screening and liver function tests were normal. 
The dose of carbamazepine was then reduced gradually over two weeks to $800 \mathrm{mg} /$ day. The asterixis was markedly improved but still present. There was minor nystagmus but the gait was steady. Serum carbamazepine had fallen to $6 \mu \mathrm{mol} / 1(1.7 \mu \mathrm{g} / \mathrm{ml})$. Four weeks later she was readmitted with a further exacerbation of her pain and partial section of the right trigeminal sensory root was performed. Carbamazepine was then withdrawn with the complete disappearance of nystagmus and asterixis.

CASE 4: ASTERIXIS WITH CEREBELLAR SYNDROME, AND OROFACIAL DYSKINESIA DUE TO DPH INTOXICATION

A 59 year old right-handed housewife was referred with a history of 'absences' for 18 months. Examination was normal. A clinical diagnosis of temporal lobe epilepsy of late onset was made, but investigations at this time revealed no obvious cause.

She was started on DPH $300 \mathrm{mg} /$ day but when seen one month later complained of lassitude, unsteadiness, and tremor of her hands. Examination at this time showed phasic nystagmus on lateral gaze with an impaired heel-toe test. She was not dysarthric but she did have involuntary lip-smacking and tongue protrusion. She showed a moderate asterixis of her outstretched hands. Serum DPH was $134 \mu \mathrm{mol} / 1$ $(33.5 \mu \mathrm{g} / \mathrm{ml})$. The drug was stopped with the complete disappearance of these abnormal signs.

She agreed to be readmitted and was subsequently rechallenged with DPH $300 \mathrm{mg} /$ day. The orofacial dyskinesia and asterixis returned without other signs of intoxication and the serum DPH level rose above the therapeutic range to $104 \mu \mathrm{mol} / 1(26 \mu \mathrm{g} / \mathrm{ml})$. Biochemical screening and liver function tests were normal.

Therapy was changed to carbamazepine 300 $\mathrm{mg} /$ day on which she was well but continued to have occasional minor seizures. The dose was increased to $600 \mathrm{mg} /$ day but she again developed minor asterixis, with a serum level of $25 \mu \mathrm{mol} / 1(5.4 \mu \mathrm{g} / \mathrm{ml})$. Subsequent reduction to $400 \mathrm{mg} /$ day resulted in a disappearance of the asterixis, the serum level falling to $5 \mu \mathrm{mol} / 1(1.5 \mu \mathrm{g} / \mathrm{ml})$.

CASE 5: ASTERIXIS WITH CEREBELLAR SYNDROME, AND OROFACIAL DYSKINESIA WITH DYSTONIA DUE TO DPH INTOXICATION

A 72 year old retired schoolteacher had occasional grand mal seizures from the age of 44 years. From this time he had taken DPH $100 \mathrm{mg} /$ day with good control of his seizures. However, over the previous year he had had more frequent fits and had therefore increased his dose of DPH to 200 and at times 300 $\mathrm{mg} /$ day. During this period his wife had noted that he was slow and apathetic and had developed abnormal movements of his face, head, and neck.

On examination he was alert and orientated, though slow, without signs of dementia. He showed a phasic nystagmus on lateral gaze and a moderate gait ataxia. There was marked lip smacking, tongue protrusion, and blepharospasm with dystonic movements of the head and neck. There was minor asterixis of the outstretched hands. Neurological examination was otherwise normal.

Biochemical screening and liver function tests including bromsulphthalein excretion were normal. Serum DPH when taking $200 \mathrm{mg} /$ day was $128 \mu \mathrm{mol} / \mathrm{l}$ $(32 \mu \mathrm{g} / \mathrm{ml})$.

The dose of DPH was reduced to $100 \mathrm{mg} /$ day and all involuntary movements disappeared within four days, the serum level of DPH falling to $19.2 \mu \mathrm{mol} / 1$ $(4.8 \mu \mathrm{g} / \mathrm{ml})$. On this dose he has remained well and free of seizures.

\section{CASE 6: LIMB CHOREA AND DYSTONIA WITH DPH} INTOXICATION

An 18 year old boy developed severe epilepsy after head injury at the age of 4 years, consisting of brief absences associated with irritability and aggression drop attacks, and generalised convulsions. His schooling up to the age of 11 years had been normak but he then attended special schools because of his severe epilepsy, borderline subnormality (full scale IQ 62), and behaviour problems. At the age of 16 years he suffered a cardiac arrest during one of his frequent episodes of status epilepticus after which there was a deterioration in seizure control and behaviour. He was admitted to hospital for inpatient assessment, taking DPH $400 \mathrm{mg} / \mathrm{day}$, carbamazepine $200 \mathrm{mg} /$ day, primidone $750 \mathrm{mg} /$ day, and diazepam $20 \mathrm{mg} /$ day.

On examination there was scarring of the eyebrows and forehead due to trauma. His facial features were coarse and there was gum hypertrophy. Neurological examination was normal.

During his stay in hospital he had several major convulsions and up to 15-20 minor seizures a day. At admission serum DPH was $28 \mu \mathrm{mol} / \mathrm{l}(7 \mu \mathrm{g} / \mathrm{ml})$ and so the dose of this drug was increased to 600 $\mathrm{mg} /$ day. Over the ensuing 10 days he became more than usually drowsy, moderately ataxic, and developed slurring dysarthria, though without sustained nystagmus. He showed fidgety choreic movements of his hands at rest and during voluntary movements, and exhibited dystonic posturing of the outstretched hands. Serum DPH at this time had risen to $172 \mu \mathrm{mol} / 1(43 \mu \mathrm{g} / \mathrm{ml})$. The DPH dose was reduced to $400 \mathrm{mg} /$ day with disappearance of 
cerebellar signs and dyskinesias within one week Serum DPH fell to $64 \mu \mathrm{mol} / 1(16 \mu \mathrm{g} / \mathrm{ml})$.

\section{CASE 7: AXIAL AND LIMB DYSTONIA POSSIBLY DUE TO DPH INTOXICATION}

A 31 year old man developed a left frontal abcess at the age of 20 years. He made a complete recovery apart from focal epilepsy which had been treated with DPH $200 \mathrm{mg} /$ day. For nine months before being seen he had been depressed and suffered frequent fits. He had received treatment with imipramine and chlordiazepoxide.

During this period he had noticed a tendency to involuntary grinding of his teeth. Because of frequent fits, the dose of DPH was increased to $300 \mathrm{mg} /$ day and phenobarbitone $60 \mathrm{mg} /$ day added. However, serum anticonvulsant level estimations before this increase in dosage showed a DPH level of $124 \mu \mathrm{mol} / 1$ $(31 \mu \mathrm{g} / \mathrm{ml})$. Over the next week the patient noted that when walking his right arm would become flexed and adducted across his chest with hyperextension of the wrist and that his right foot would become inverted. His speech became more slurred, the grinding movements of the jaw more pronounced and, on occasion, his tongue would protrude. The left limbs were unaffected apart from occasional contortion of the little finger and inversion of the foot.

When seen at this time he showed a picture typical of torsion dystonia. His jaw deviated to the left on talking and his head twisted spasmodically in the same direction. His right arm was contorted by hyperpronation spasms and also showed a fast tremor. When walking he developed a scoliosis to the left, fidgety movements of both hands, and dystonic inversion of the right foot and to a lesser extent the left foot.

Full investigations including EMI scan and studies of copper metabolism failed to reveal any cause for the dystonia other than the raised serum DPH. This drug was withdrawn but in spite of this his dystonic symptoms persisted and were possibly more severe, until tetrabenazine was added, leading to a dramatic improvement. He continued to suffer frequent fits in spite of treatment with primidone, carbamazepine, and pheneturide, and after some of these there was a brief exacerbation of his mild dystonic symptoms which were still present some three months after therapy with DPH ceased.

\section{CASE 8: AXIAL AND LIMB DYSTONIA POSSIBLY} PRECIPITATED BY SULTHIAME

A 16 year old girl who, in spite of normal birth and early development, was mentally retarded, developed minor epilepsy with typical spike-wave EEG activity at the age of 4 years. At the age of 9 years, sulthiame had been added to her previous anticonvulsant, DPH, and at this time she suddenly developed dystonic posturing of the right arm and leg. Her head twisted to the left. The sulthiame was stopped after two weeks, but dystonic posturing had persisted and, indeed, become worse over the ensuing years, even though all anticonvulsants had been stopped at the age of 12 years, when her epilepsy remitted. The left arm and leg had become mildly affected by dystonic posturing. Investigations had failed to reveal any cause for her dystonia.

\section{DISCUSSION}

TYPES OF DYSKINESIA PRECIPITATED BY ANTICONVULSANT TOXICITY AND THEIR FREQUENCY

Among our patients, asterixis was the commonest dyskinesia seen, occurring in cases 1-5. Asterixis has also been described in four other cases reported in the literature and may have been present in two other patients (Table 1). Spontaneous myoclonic jerks were associated with asterixis in at least two and possibly four of these reported cases.

An orofacial dyskinesia was observed in two of our patients (cases 4 and 5) and similar dyskinesias involving the mouth, jaw and tongue have been reported in 11 other patients (Table 1). Chorea of the limbs was seen in cases 6 and 7 and has been reported in 12 other patients. (We have taken reports of 'choreoathetosis' to indicate significant chorea) (Table 1).

Dystonic movements and postures clearly related to anticonvulsant intoxication were observed in cases 5 and 6 and may have been precipitated by such intoxication in two others (cases 7 and 8). In case 8, the addition of sulthiame may have induced DPH intoxication (Houghton and Richens, 1974). Obvious dystonia has been reported in nine other cases (Table 1).

These dyskinesias have been accepted as rare manifestations of anticonvulsant toxicity. However, we are impressed by the frequency with which we have observed such disorders, all the cases reported here having been seen over an 18 month period.

\section{DRUGS RESPONSIBLE}

Asterixis Sometimes associated with spontaneous myoclonic jerks, asterixis has been precipitated by intoxication with DPH, primidone, phenobarbitone, and carbamazepine, in our material, and by DPH in those cases reported in the literature.

Orofacial dyskinesias, chorea, and dystonia These have been precipitated only by DPH, with the single 
exception of the patient reported by Kirschberg (1975) in whom the addition of ethosuximide to DPH appeared reponsible.

Where blood anticonvulsant levels were recorded, dyskinesias due to DPH occurred with plasma levels of 106 to $368 \mu \mathrm{mol} / 1(26-92 \mu \mathrm{g} / \mathrm{ml})$. Nystagmus and other signs of cerebellar toxicity usually appear when the plasma DPH level exceeds $80 \mu \mathrm{mol} / \mathrm{l}$ (Buchthal and Lennox-Buchthal, 1972a). In the two cases of asterixis caused by phenobarbitone, the plasma level was $269 \mu \mathrm{mol} / \mathrm{l}(64 \mu \mathrm{g} / \mathrm{ml})$ and $395 \mu \mathrm{mol} / \mathrm{l}(94 \mu \mathrm{g} / \mathrm{ml})$ (upper limit of therapeutic range is about $150 \mu \mathrm{mol} / \mathrm{l}$ $(35 \mu \mathrm{g} / \mathrm{ml}))$, although in one case asterixis persisted at much lower serum levels. In the two cases of asterixis caused by carbamazepine, the plasma level was 23 and $41 \mu \mathrm{mol} / \mathrm{l}(5.4$ and $9.7 \mu \mathrm{g} / \mathrm{ml})$. Neurotoxic effects of this drug usually appear above $25 \mu \mathrm{mol} / 1$ $(6 \mu \mathrm{g} / \mathrm{ml})$ (Reynolds, 1975b).

\section{OTHER TOXICITY ASSOCIATED WITH DYSKINESIAS}

In every case of asterixis reported there were additional signs of cerebellar toxicity in the form of nystagmus and ataxia in all, and dysarthria in most. Mental confusion was also noted in four of the 11 patients described. However, in two of our cases asterixis was the only sign of toxicity when rechallenged with the offending drug (cases 1 and 4).

Similar signs of cerebellar toxicity were noted in the majority of patients with other forms of dyskinesias, but nystagmus was not evident in seven of the 19 patients with orofacial dyskinesias, chorea, or dystonia in whom it was looked for. Ataxia and dysarthria were not apparent in four patients, and in others may well have been due to the dyskinesias rather than to cerebellar dysfunction. Thus, as has recently been recognised for DPH-induced mental changes (Reynolds, 1975a), dyskinesias may occur with little or no evidence of cerebellar dysfunction. Such toxicity is therefore easily overlooked unless blood levels of the drug are determined. When dyskinesias and mental changes occur together, especially in brain damaged retarded patients, the clinical picture may be mistaken for a progressive degenerative disorder (Logan and Freeman, 1969; Reynolds, 1975a).

\section{CLINICAL FACTORS RESPONSIBLE FOR}

ANTICONVULSANT-INDUCED DYSKINESIAS

Apart from the proven association of such dyskinesias with anticonvulsant intoxication, it has been suggested that they appear more readily in epileptics with known cerebral pathology (Logan and Freeman, 1969; Shuttleworth et al., 1974; Ahmad et al., 1975). While many of the cases reported indeed had neurological deficits in addition to their epilepsy, $\underset{\mathbb{Q}}{Z}$ some have been otherwise normal people. Thus, at least three of our patients (cases 2, 4, and 5) had no other neurological deficit, and asterixis occurred in 0 one patient with tic douloureux (case 3). At present 0 there is insufficient information to decide whether anticonvulsant-induced dyskinesias are more readily provoked in brain-damaged epileptics, but such cerebral pathology is not essential. The age of the patient, type or duration of epilepsy, and the duration of therapy do not appear to play a significant role in the genesis of anticonvulsant-induced dyskinesias.

PHARMACOLOGICAL BASIS OF ANTICONVULSANTINDUCED DYSKINESIAS

Asterixis Asterixis was originally reported in $\vec{\circ}$ patients with liver disease (Adams and Foley, 1949), $\overrightarrow{.}$ but is now known to be a common feature of a variety of metabolic and drug-induced encephalopathies (Leavitt and Tyler, 1964), to which anticonvulsant $\frac{7}{0}$ intoxication must be added. It is not possible relate any specific neurochemical changes to the induction of asterixis.

Orofacial dyskinesias, limb chorea, and dystoni $\stackrel{0}{\overrightarrow{0}}$ These abnormalities, caused by intoxication wit DPH (but not, apparently, with other anticonvup sants), are very similar to the tardive dyskinesias seen in patients on chronic neuroleptic drug therap\& (Marsden et al., 1975). The tardive dyskinesias produced by neuroleptics most commonly consist 0 an orofacial dyskinesia which may occur alone but which is often associated with limb chorea and dystonia. The dyskinesia seen in our cases 4 and 5 could easily have been mistaken for neurolepticinduced tardive dyskinesias. This suggests that both DPH and neuroleptic drugs cause dyskinesias by a similar mechanism, but there are, of course, striking differences between the two groups of drugs, both in their therapeutic properties and in their side-effects (Table 3).

The mechanisms by which neuroleptics cause tardive dyskinesias are not understood. It is currently believed that such dyskinesias (as well as the antipsychotic action of these drugs and the Parkinsonism and akathisia that they produce) are due to their capacity to block cerebral dopamine receptors (Marsden, 1975). Such an action can be demonstrated by a variety of different animal experiments. DPH has been found to have actions similar to those of neuroleptics in some, but not all, of these animal models (Table 4). We have also observed a trend towards raised CSF levels of homovanillic acid in drug treated epileptics with 'therapeutic' and toxic blood levels of DPH and phenobarbitone (Chadwick 
TABLE 3

COMPARISON OF DPH AND NEUROLEPTICS IN HUMANS

\begin{tabular}{lcc}
\hline & $D P H$ & Neuroleptics \\
\hline $\begin{array}{l}\text { Side-effects } \\
\text { 1. Dyskinesias } \\
\text { a. dose related }\end{array}$ & Orofacial dyskinesia, Limb chorea (dystonia) & Orofacial dyskinesia, Limb chorea (dystonia) \\
$\begin{array}{l}\text { b. reversible } \\
\text { 2. Parkinsonism }\end{array}$ & Yes & No \\
3. Akathisia & Yes* & Not in about $50 \%$ \\
4. Cerebellar syndrome & Not & Yes \\
5. Asterixis & No & No \\
Therapeutic effects & Yes & No \\
1. In epilepsy & Yes & May exacerbate epilepsy \\
2. In mental illness & & Antipsychotic \\
\hline
\end{tabular}

* In the two cases of dystonia apparently precipitated by DPH intoxication reported here (cases 7 and 8 ), it is by no means certain that DPH was responsible for the persistence of the dystonia. No other examples of persistent DPH-induced dyskinesias are known to us.

† Although Parkinsonism is not reported with DPH, it does diminish the therapeutic effects of L-dopa in Parkinson's disease (Mendez et al., 1975).

\section{TABLE 4}

COMPARISON OF EVIDENCE FOR DOPAMINE RECEPTOR BLOCKADE BY DPH AND NEUROLEPTICS

\begin{tabular}{|c|c|c|}
\hline Animal experiments & $D P H$ & Neuroleptics \\
\hline $\begin{array}{l}\text { 1. Inhibition of turning behaviour induced by apomorphine and L-dopa in rodents with unilateral lesions of the } \\
\text { nigro-striatal pathway }\end{array}$ & Present $^{1}{ }^{2}$ & Present“ \\
\hline 2. Turning behaviour produced by unilateral striatal injection of drug and systemic administration of apomorphine & Present $^{1}$ & Present" \\
\hline 3. Inhibition of reversal of akinesia in reserpinised animals by apomorphine & Absent ${ }^{1}$ & Present" \\
\hline 4. Inhibition of apomorphine stereotypies & Absent $^{1}$ & Present ${ }^{7}$ \\
\hline 5. Inhibition of uptake and binding of dopamine in vitro & Present $^{3}$ & Present $^{8}$ \\
\hline 6. Increase in brain dopamine metabolites & Absent ${ }^{1}$ & Present 4 \\
\hline
\end{tabular}

${ }^{2}$ Elliott, et al. (J. Pharm. Pharmac., in press)

${ }^{2}$ Mendez et al.(1975)

${ }^{3}$ Hadfield (1972)

4 Anden et al. (1970)

' Costall et al.(1972)
' Marsden et al.(1974)
? Fog(1972)
${ }^{8}$ Burt et al.(1975)

et al., 1975), but this effect is much less marked than that of the drugs on serotonin metabolism (Chadwick et al., 1976). This suggests that DPH shares with neuroleptics the capacity to block the effects of dopamine in some circumstances, but the differences between the two groups of drugs indicate that this action is unlikely to be identical with that of neuroleptics. At present it is impossible to specify the exact pharmacological effect of DPH on cerebral dopamine systems and the subject deserves further study.

We are grateful to Professor G. W. Fenton, Professor W. I. McDonald, and Dr J. Foley for allowing us to study and report on their patients, to M. Laundy and
L. Vydelingum for technical assistance, and to Parke-Davis and Ciba-Geigy for financial support.

\section{REFERENCES}

Adams, R. D., and Foley, J. (1949). Neurological changes in more common types of severe liver disease. Transactions of the American Neurological Association, 74, 217-219.

Ahmad, S., Laidlaw, J., Houghton, G. W., and Richens, A. (1975). Involuntary movements caused by phenytoin intoxication in epileptic patients. Journal of Neurology, Neurosurgery, and Psychiatry, 38, 225-231.

Anden, N-E., Butcher, S. G., Corrodi, H., Fuxe, K., and 
Ungerstedt, U. (1970). Receptor activity and turnover of dopamine and noradrenaline after neuroleptics. European Journal of Pharmacology, 11, 303-314.

Buchthal, F., and Lennox-Buchthal, M. A. (1975a). Phenobarbital-Relation of anticonvulsant effect to concentration in serum. In Antiepileptic Drugs, pp. 335343. Edited by D. M. Woodbury, J. K. Penry, and R. P. Schmidt. Raven Press: New York.

Buchthal, F., and Lennox-Buchthal, M. A. (1975b). Diphenylhydantoin-Relation of anticonvulsant effect to concentration in serum. In Antiepileptic Drugs, pp. 193-209. Edited by D. M. Woodbury, J. K. Penry, and R. P. Schmidt. Raven Press: New York.

Burt, D. R., Enna, S. J., Creese, I., and Snyder, S. H. (1975). Dopamine receptor binding in corpus striatum of mammalian brain. Proceedings of the National Academy of Sciences, 72, 4655-4659.

Chadwick, D., Jenner, P., and Reynolds, E. H. (1975). Amines, anticonvulsants and epilepsy. Lancet, 1, 473476.

Chadwick, D., Jenner, P., and Reynolds, E. H. (1976). Serotonin metabolism in human epilepsy. Annals of Neurology. (In press.)

Costall, B.. Naylor, R. J., and Olley, J. E. (1972). Catalepsy and circling behaviour after intracranial injections of neuroleptic, cholinergic and anticholinergic agents into the caudate-putamen, globus pallidus and substantia nigra of rat brain. Neuropharmacology, 11, 645-663.

Engel, J., Cruz, M. E., and Shapiro, B. (1971). Phenytoin encephalopathy? Lancet, 2, 824-825.

Fog, R. (1972). On stereotypy and catalepsy: studies on the effects of amphetamines and neuroleptics in rats. Acta Neurologica Scandinavica, 48, suppl. 50, 1-66.

Gerber, N., Lynn, R., and Oates, J. (1972). Acute intoxication with 5,5-diphenylhydantoin associated with impairment of biotransformation. Annals of Internal Medicine, 77, 765-771.

Hadfield, M. G. (1972). Uptake and binding of catecholamines. Effects of diphenylhydantoin and a new mechanism of action. Archives of Neurology (Chic.), 26, 78-84.

Houghton, G. W., and Richens, A. (1974). Phenytoin intoxication induced by sulthiame in epileptic patients. Journal of Neurology, Neurosurgery, and Psychiatry, 37, 275-281.

Kirschberg, G. J. (1975). Dyskinesia-an unusual reaction to ethosuximide. Archives of Neurology (Chic.), 32, 137-138.

Kooiker, J. C., and Sumi, S. M. (1974). Movement disorder as a manifestation of diphenylhydantoin intoxication. Neurology (Minneap.), 24, 68-71.
Kupferberg, H. J. (1970). Quantitative estimation of diphenylhydantoin, primidone and phenobarbitone in plasma by gas liquid chromatography. Clinica Chimica Acta, 29, 283-288.

Leavitt, S., and Tyler, H. R. (1964). Studies in asterixis. Archives of Neurology (Chic.), 10, 360-368.

Logan, W. J., and Freeman, J. M. (1969). Pseudodegenerative disease due to diphenylhydantoin intoxication. Archives of Neurology (Chic.), 21, 631-637.

McLellan, D. L., and Swash, M. (1974). Choreoathetosis and encephalopathy induced by phenytoin. British Medical Journal, 2, 204-205.

Marsden, C. D. (1975). The neuropharmacology of abnormal involuntary movement disorders (the dyskinesias). In Modern Trends in Neurology-6, pp. 141-166. Edited by D. Williams. Butterworths: London.

Marsden, C. D., Dolphin, A., Duvoisin, R., Jenner, P., and Tarsy, D. (1974). Role of noradrenaline in levodopa reversal of reserpine akinesia. Brain Research, 77, 521525.

Marsden, C. D., Tarsy, D., and Baldessarini, R. J. (1975). Spontaneous and drug-induced movement disorders in psychotic patients. In Psychiatric Aspects of Neurologicali Disease, pp. 219-266. Edited by F. D. Benson and D..$+\vec{N}$ Blumer. Grune and Stratton: New York.

Mendez, J. S., Cotzias, G. C., Mena, I., and Papavasilou, P. S. (1975). Diphenylhydantoin: blocking of levodopa effects. Archives of Neurology (Chic.), 32, 44-46.

Murphy, M. J., and Goldstein, M. N. (1974). Diphenyl-O hydantoin-induced asterixis. Journal of the American Medical Association, 229, 538-540.

Peters, H. A., Eichmann, P. L., Price, J. M., Kozelka, F. A. and Reese, H. H. (1966). Abnormal copper and tryptophan metabolism and chelation therapy in anticonvulsant drug intolerance. Diseases of the Nervous System, 28, 97-107.

Reynolds, E. H. (1975a). Chronic antiepileptic toxicity: a review. Epilepsia, 16, 319-352.

Reynolds, E. H. (1975b). Carbamazepine neurotoxicity. In Complex Partial Seizures and their Treatment, pp. 345-353. Edited by J. K. Penry and D. Daly. Advances in Neurology, vol. 11. Raven Press: New York.

Shuttleworth, E., Wise, G., and Paulson, G. (1974). Choreoathetosis and diphenylhydantoin intoxication. Journal of the American Medical Association, 230, 1170-1171.

Toseland, P. A., Grove, J., and Berry, D. J. (1972). An isothermic GLC determination of the plasma levels of carbamazepine, diphenylhydantoin, phenobarbitone and primidone. Clinica Chimica Acta, 38, 321-328.

Woodbury, D. M., Penry, J. K., and Schmidt, R. P. (1972). Antiepileptic Drugs. Raven Press: New York. 